\title{
Bioprospecting filamentous fungi from Puerto Rico for biotechnological applications
}

\begin{abstract}
Novel fungal isolates from Puerto Rico were collected, morphologically identified, axenically cultured, and examined for lignolytic activity. Nine isolates were selected for ABTS differential media assays and rDNA sequencing and identification, five of which exhibited lignolytic activity. The results highlight the need for further conservation and studies on the potential utility of understudied fungi isolated from Puerto Rico. Our study is the first to collect and identify fungi from the island of Puerto Rico with the purpose of examining cultures for potential biotechnological applications. We are the first to demonstrate that wild isolated strains of fungi from Puerto Rico are a potential source of novel fungi to improve current biopulping, bioethanol, and bioremediation technologies
\end{abstract}

Keywords: bioprospecting, Puerto Rico, bioremediation, bioethanol, fungi
Volume 6 Issue 6 - 2018

\author{
Richard L Giles,' Luis J Barrios Babilonia,' \\ David Gonzalez Vargas,' Juan G Abreu \\ Ramos,' Carlos A Betancourt Velez,' Eliseo A \\ Lebron Burgos,' Arnaldo J Roman Acevedo,' \\ Omar M Zayas Cruz,' Jeffrey C Zackeru² \\ 'Department of Science and Technology, Inter-American \\ University of Puerto Rico, USA \\ ${ }^{2}$ Department of Biology, University of North Carolina at \\ Charlotte, USA
}

Correspondence: Richard L. Giles, Department of Science and Technology, Inter-American University of Puerto Rico,Arecibo Campus, P.O. Box 4050, Arecibo, Puerto Rico, 00614 USA, Tel +18284610665, Email gilesr@clevelandcc.edu

Received: April 27, 2017 | Published: December 26, 2018

\section{Introduction}

To date, few Puerto Rican wood decay fungal species and strain isolates have been studied for biotechnology. Wood decay fungi have narrow growth condition requirements such as optimal temperatures for vegetative growth, high humidity for sporocarp formation, lignin type, and substrate specific carbohydrates for metabolic functions. Saprobic wood decay fungi are highly host plant specific due to these requirements for growth. Therefore, fungal species habitat range mirrors the geographical distribution of the vascular plant host range and a 6:1 fungus to plant ratio has been observed. ${ }^{2-4}$ The biodiversity of fungal species within a geographical region is also reflective of plant diversity although much less study has been devoted to cataloging new fungal taxa. ${ }^{5-9}$ While fungal diversity has not been significantly explored in many areas of the world, extrapolations of small habitat fungal inventories provide insight into the potential diversity of understudied areas. Notably, intensive cataloging studies reveal surprisingly high numbers of fungal taxa within small geographic areas. For example, examined leaf litter under five trees in Panama contained 500 different fungal species and a study of palms collected 1,580 Ascomycete species (1,185 were previously undiscovered). ${ }^{10,11}$

Novel methods utilizing fungal decay mechanisms have been previously examined using as methods for sustainable and economical methods of paper production, chemical remediation, and biofuels produciton. ${ }^{12-21}$ However, none of the abundant wild fungal species in Puerto Rico have been isolated for use in this emerging field of biotechnology. Therefore, we propose collecting and characterizing fungal species in the biologically diverse island of Puerto Rico in order to further this area of promising research. To our knowledge, fungi from Puerto Rico have not been isolated and examined for the utility in the varied fields of lignocellulosic degradation technologies. This study combines a fundamental biodiversity study with a screening for an applied microbial degradation ability to progress the study of these unique and potentially useful fungi for biotechnology. To test these hypotheses novel wild isolates fungi from Puerto Rico were identified by morphology and rDNA sequencing, axenically cultured for study, and screened for lignolytic activity utilizing differential media.

\section{Methods}

\section{Wild fungal isolate collection and identification}

Reproductive sporocarps (basidiocarps) were collected in wooded areas in Puerto Rico, USA and returned to the laboratory for inspection. Macroscopic and microscopic characteristics were used to identify the collected specimens to morphological species using standard taxonomic monographs and treatments as previously described. ${ }^{21-25}$ Macroscopic characters such as basidiocarp type (e.g. resupinate, applanate), presence/absence of stipe, and margin growth were used for identification. Micro morphology such as context tissue hyphal types (e.g. skeletal, generative) were identified using light microscopy and staining reaction techniques (e.g. Melzner's reagent). ${ }^{22,23,25}$ Once identified to morphospecies, sporocarps were split under aseptic conditions and inner tissue samples were inoculated onto non-selective fungal media $\left(20 \mathrm{~g}\right.$ malt extract, $10 \mathrm{mg}$ tetracycline, and $20 \mathrm{~g}_{\text {agar L }} \mathrm{L}^{-1}$ in deionized water) and incubated in darkness at $28^{\circ} \mathrm{C}$ for $7 \mathrm{e} 10$ days. ${ }^{26,27}$ Hyphal colonies were then serially subcultured on new agar plates without antibiotic and maintained as pure cultures at $28^{\circ} \mathrm{C}$ in darkness on modified malt extract agar (20g malt extract and $20 \mathrm{~g}_{\text {agar } \mathrm{L}^{-1}}$ in deionized water) until use. Axenic fungal isolates that exhibited rapid growth in modified malt extract agar were considered candidates for further study and elucidated using ABTS and rDNA identification.

\section{ABTS Agar plate assays for lignolytic activity}

Square agar plugs $\left(1 \mathrm{~cm}^{2}\right)$ cut from stock malt extract agar plate cultures were used to aseptically inoculate each differential media assay plate. To examine the ability of each fungal isolate to depolymerize ABTS, modified Malt Extract Agar containing ABTS (1 g 2,2'-azino-bis(3-ethylbenzothiazoline-6-sulphonic acid), 20g malt extract, and $20 \mathrm{~g}$ agar $\mathrm{L}^{-1}$ in deionized water). ${ }^{28}$ All treatment combinations and sterile controls were conducted in triplicate. The assay plates were incubated at $28^{\circ} \mathrm{C}$ in darkness for 21 days to allow adequate time for the fungal mycelia to spread across the surface of each plate, and observed for color changes within the media. ${ }^{28}$

\section{rDNA Identification}

Fungal DNA was extracted from cultured hyphae of isolates 
using techniques modified from Lõoke et al. ${ }^{29}$ Approximately $100 \mathrm{mg}$ of fungal mycelium was mechanically ground using a rod, mixed with $200 \mathrm{~mL}$ of $200 \mathrm{mM}$ lithium acetate (LiOAc) with $1 \%$ sodium dodecyl sulfate (SDS), and then incubated for $15 \mathrm{~min}$ at $70^{\circ} \mathrm{C}$. After incubation, $300 \mathrm{~mL}$ of $95 \%$ ethanol was added and the sample was immediately vortex-mixed (15s) and then pelleted by centrifugation $(5 \mathrm{~min}, 15,000 \mathrm{~g})$. The supernatant was then replaced with $500 \mathrm{~mL}$ of $70 \%$ ethanol and the pellet was resuspended by vortex mixing $(30 \mathrm{~s})$ followed by sedimentation by centrifugation as above. The supernatant was then discarded and the pellet was resuspended in $100 \mathrm{~mL}$ of $\mathrm{H}_{2} \mathrm{O}$ resulting pellet was resuspended in supernatant was removed and the sample was resuspended in $100 \mathrm{~mL}$ of $\mathrm{H}_{2} \mathrm{O}$. This genomic DNA from each strain was used as template for PCR amplification of the ITS region of the rDNA using primers ITS1-F (sequence: CTTGGTCATTTAGAGGAAGTAA) and ITS4-B (sequence: CAGGAGACTTGTACACGGTCCAG), previously described as specific for amplification of the entire ITS region (ITS1-5.8S-ITS2) of Basidiomycetes fungi. ${ }^{20,30-32}$ Individual PCR reactions consisted of $60 \mathrm{ng}$ of template DNA, $25 \mu \mathrm{L}$ of GoTaq Green Master Mix (Promega Corp., Madison, WI, USA), 100ng of each primer, and $2.5 \mathrm{~mL}$ DMSO with reaction parameters as follows: initial denaturing at $94^{\circ} \mathrm{C}$ for $2 \mathrm{~min}, 30$ cycles of $94^{\circ} \mathrm{C}$ for $30 \mathrm{~s}, 56^{\circ} \mathrm{C}$ for $45 \mathrm{~s}, 72^{\circ} \mathrm{C}$ for $2: 15$, followed by $72^{\circ} \mathrm{C}$ for $5 \mathrm{~min}$. PCR products were visualized and size checked using gel electrophoresis, and purified using polyethylene glycol (PEG) (Thermo Fisher Scientific Inc., Waltham, MA, USA) and ethanol following Fawcett \& Parrow. ${ }^{33}$ Cleaned products were mixed with appropriate sequencing primers and sequenced in both directions using Applied Biosystems BigDye version 3.1 (GENEWIZ, Inc., South Plainfield, NJ, USA). Resulting sequence assemblies were queried using advanced, nongapped NCBI BLAST search with expectation frequency set to 0.0001 and no filtering for low complexity as previously described. ${ }^{34}$ The highest BLAST bit score and maximum identity similarity were used to determine closest available taxon to confirm morphological identification. ${ }^{35}$

\section{Results and discussion}

\section{Identification of novel fungal isolates and evaluation of lignolytic activity}

Wild isolates brought into pure culture for these studies were unambiguously identified to morphospecies by distinct features of their basidiocarp morphology, and identity based on ITS rDNA sequence comparisons confirmed this morphological classification (Table 1). ${ }^{20,22,23,35,36}$ Among the isolates collected for study, fungi from the taxonomic phyla Ascomycota and Basidiomycota exhibited lignolytic activity in the ABTS media suggesting laccase mediated enzymatic hydrolysis of the compound (Figure $1 \& 2$, Table 1 ) ${ }^{28}$ Further analysis of mechanism (e.g. enzymatic) is required to characterize the differences between lignolytic isolates. ${ }^{12,37}$ The bioprospecting of Puerto Rico's fungal biodiversity will significantly contribute to future biofuel and bioremediation by making available new species and novel strains for examination. While it is clear that a collection and characterization of fungal taxa of Puerto Rico described in this study is beneficial to understanding forest ecology, it is also important to isolate and culture these organisms for future study. Collection of live cultures will allow future study of decay fungi that may not be obtainable in the future due to habitat loss, providing a snapshot of decay ecology within several study sites. Fungal biodiversity loss due to threat of disease and human encroachment has not been studied in regards to Puerto Rico, however inferences of potential loss can be made because of the known relationship between wood decay fungal diversity and host woody plant diversity. ${ }^{38}$ Because of this correlation, it is apparent that the decline of tree biodiversity due to disease and loss of habitat strongly suggests that wood decay fungal species may also be declining. Of particular concern is the potential loss of undiscovered and uncharacterized fungal species within the highly specialized forest ecotypes inside Puerto Rico's forests. Habitat disturbance such as the introduction of non-native disease and human disturbance has been shown to negatively affect the forest biodiversity and ecology of Puerto Rico. ${ }^{39,40}$ For example, the well known historical example of Cryphonectria parasitica (chestnut blight) which killed native Castanea dentata (American chestnut) tree stands, the dominant hardwood forest species and the major producer of hard mast (e.g. acorns). ${ }^{41}$ More recent examples of destructive plant pathogens affecting the cove hardwood and spruce-fir forests include dogwood anthracnose and the fir wooly adelgid. Discula destructive (dogwood anthracnose) has killed Cornus florida (flowering dogwood trees) within the Great Smoky Mountain National Park cove forests, significantly changing the understory plant ecology over the last two decades, and possibly affecting nutrient cycling. ${ }^{42,43}$ These ecological pressures have substantial cascading effects on forest ecology and therefore fungal biodiversity. It is therefore imperative to promote the conservation of these unique fungi and forest ecotypes by careful collection, culturing, and study. Our study is the first to collect and identify fungi from the island of Puerto Rico and examine cultures for potential biotechnological applications.

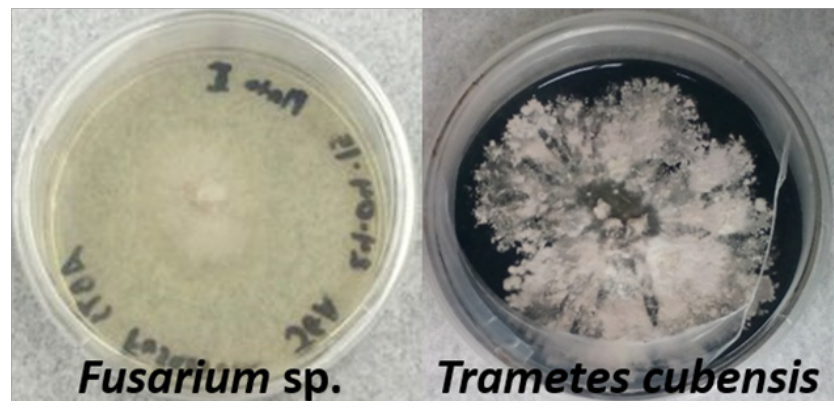

Figure I Differential media with modified Malt Extract Agar containing ABTS (2,2'-azino-bis(3-ethylbenzothiazoline-6-sulphonic acid) were used to examine the lignolytic capability of fungal isolates from Puerto Rico. The agar turns green due to the oxidation of ABTS.An isolate of Trametes cubensis exhibited significant $A B T S$ oxidation compared to a Fusarium sp. isolate showing no indication of ABTS depolymerization.

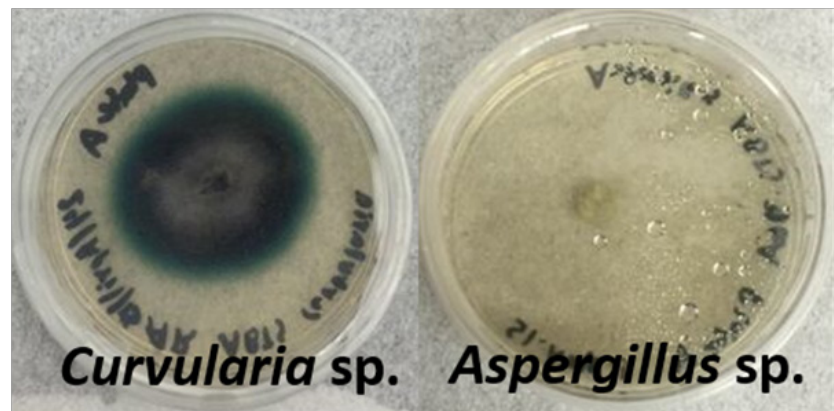

Figure 2 Differential media with modified Malt Extract Agar containing ABTS (2,2'-azino-bis(3-ethylbenzothiazoline-6-sulphonic acid) were used to examine the lignolytic capability of fungal isolates from Puerto Rico. The agar turns green due to the oxidation of ABTS. An isolate of Curvularia sp. exhibited significant $A B T S$ oxidation compared to an Aspergillus sp. isolate showing no indication of ABTS depolymerization. 
Table I Identified fungal isolates collected from Puerto Rico and ABTS differential media assay results. Fungi with ABTS depolymerization activity denoted by $(+)$. A (-) indicates no ABTS depolymerization observed.

\begin{tabular}{lll}
\hline Taxonomic groups and fungal species & Extracellular ABTS-oxidizing activity \\
\hline \multirow{2}{*}{ Basidiomycota } & Trametes cubensis & + \\
& Trametes pubescens & + \\
& Lasidiplodia pseudotheobromae & + \\
& Aspergillus sp. & - \\
Cladosporium sp. & + \\
Ascomycota & Fusarium $\mathrm{sp}$. & - \\
& Curvularia sp. & + \\
Zygomycota & Cunninghamella sp. & - \\
\hline
\end{tabular}

\section{Conclusion}

Novel fungal isolates from Puerto Rico were identified and examined for lignolytic activity. We are the first to demonstrate that wild isolated strains of fungi from Puerto Rico are a potential source of novel fungi to improve current biopulping and bioremediation technologies. The results highlight the need for further studies on the potential utility of understudied fungi isolated from Puerto Rico.

\section{Acknowledgments}

The authors would like to thank Paul McKenzie for laboratory assistance.

\section{Conflicts of interest}

Authors declare that there is no conflict of interest.

\section{References}

1. Eriksson K, Blanchette RA, Ander P. Microbial and Enzymatic Degradation of Wood and Wood Components. New York: SpringerVerlag; 1990.

2. Overholts LO. The Polyporacea of the United States, Alaska and Canada. Ann Arbor: University of Michigan Press; 1953.

3. Lowe JL. Polyporaceae of North America. College of Forestry Technology Publications, New York: State University; 1966.

4. Hawksworth DL. The fungal dimension of biodiversity: magnitude, significance, and conservation. Mycological Research. 1991;95(6):641655 .

5. Hawksworth DL, Rossman AY. Where are all the undescribed fungi? Phytopathology. 1997;87(9):888-891.

6. Gilbert GS, Sousa WP. Host specialization among wood-decay polypore fungi in a Caribbean mangrove forest. Biotropica. 2002;34(3):396-404.

7. Ferrer A, Gilbert GS. Effect of tree host species on fungal community composition in a tropical rain forest in Panama. Diversity and Distributions. 2003;9(6):455-468.

8. Odor P, Heilmann-Clausen J, Christensen M, et al. Diversity of dead wood inhabiting fungi and bryophytes in semi-natural beech forests in Europe. Biological Conservation. 2006;131(1):58-71.

9. Mueller GM, Schmit JP. Fungal biodiversity: what do we know? What can we predict?. Biodiversity and Conservation. 2007;16(1):1-5.
10. Cornejo FH, Varela A, Wright SJ. Tropical forest litter decomposition under seasonal drought: nutrient release, fungi and bacteria. Oikos. 1994;70(2):183-190.

11. Piepenbring M. Inventoring the fungi of Panama. Biodiversity and Conservation. 2007;16(1):73-84.

12. Blanchette R. Screening wood decayed by white rot fungi for preferential lignin degradation. Applied and Environmental Microbiology. 1984;43:647-653.

13. Scott G, Akhtar M, Lentz M, et al. New technology for papermaking: commercializing biopulping. Tappi Journal. 1998;81(11):220-225.

14. Arora D, Bridge PD, Bhatnagar D. Handbook of Fungal Biotechnology. Vol 20. 2nd Ed. New York: Marcel Dekker Inc; 2004.

15. Tortella GR, Rubilar O, Gianfreda L, et al. Enzymatic characterization of Chilean native wood-rotting fungi for potential use in the bioremediation of polluted environments with chlorophenols. World Journal of Microbiology and Biotechnology. 2008;24:2805-2818.

16. Couto RS. Dye removal by immobilized fungi. Biotechnol Adv. 2009;27(3):227-235.

17. Vimala R, Nilanjana D. Biosorption of cadmium (II) and lead (II) from aqueous solutions using mushrooms: a comparative study. Journal of Hazardous Materials. 2009;168(1):376-382.

18. Fissore A, Carrasco L, Reyes P, et al. Evaluation of a combined brown rot decay-chemical delignification process as a pretreatment for bioethanol production from Pinus radiata wood chips. J Ind Microbiol Biotechnol. 2010;37(9):893-900.

19. Rasmussen MI, Shrestha P, Khanal SK, et al. Sequential saccharification of corn fiber and ethanol production by the brown rot fungus Gloephyllum trabeum. Bioresour Technol. 2010;101(10):3526-3533.

20. Giles RL, Galloway ER, Zackeru JC, et al. Two stage fungal biopulping solubilizes lignocellulosic carbohydrates without supplemental enzymatic hydrolysis. International Biodeterioration \& Biodegradation. 2014;86(Part C):265-271.

21. Giles RL, Zackeru JC, Galloway ER, et al. Single versus simultaneous species treatment of wood with Ceriporiopsis subvermispora and Postia placenta for ethanol applications, with observations on interspecific growth inhibition. International Biodeterioration \& Biodegradation. 2015;99:66-72.

22. Gilbertson RL, Ryvarden L. North American Polypores. Vol 1. Oslo: Fungiflora; 1986. 
23. Gilbertson RL, Ryvarden L. North American Polypores. Vol 2. Oslo: Fungiflora; 1987.

24. Jung HS. Wood-rotting Aphyllophorales of the southern Appalachian spruce-fir forest. Bibliography of Mycology. 1987;119:1-260.

25. Vilgalys R, Smith A, Sun BL, et al. Intersterility groups in the Pleurotus ostreatus complex from the continental United States and adjacent Canada. Canadian Journal of Botany. 1993;71(1):113-128.

26. Clausen CA, Kartal SN. Accelerated detection of brown-rot decay: comparison of soil block test, chemical analysis, mechanical properties, and immunodetection. Forest Products Journal. 2003;53(11-12):90-94.

27. Yang DQ. Isolation of wood-inhabiting fungi from Canadian hardwood logs. Can J Microbiol. 2005;51(1):1-6.

28. Pointing SB. Qualitative methods for the determination of lignocellulolytic enzyme production by tropical fungi. Fungal Diversity. 1999;2:17-33.

29. Lõoke M, Kristjuhan K, Kristjuhan A. Extraction of genomic DNA from yeasts for PCR-based applications. Biotechniques. 2011;50(5):325328.

30. White TJ, Bruns T, Lee S, et al. Amplification and direct sequencing of fungal ribosomal RNA genes for phylogenetics. In: Innis MA, Gelfand DH, Sninsky JJ, White TJ, (Eds.), PCR Protocols: A Guide to Methods and Applications. New York: Academic Press Inc; 1990. 315-322 p.

31. Gardes M, Bruns TD. ITS primers with enhanced specificity for Basidiomycetes: application to the identification of mycorrhizae and rusts. Mol Ecol. 1993;2(2):113-118.

32. Priyadarsini RI, Bhuvaneswari V, Kumar KS. Isolation, identification and phylogenetic analysis of white rot fungus and heterloguous expression of gene encoding laccase. Journal of Applied Sciences in Environmental Sanitation. 2011;6:69-83.

33. Fawcett RC, Parrow MW. Cytological and phylogenetic diversity in freshwater Esoptrodinium/Bernardinium species (Dinophyceae). $J$ Phycol. 2012;48(3):793-807.
34. Henry T, Iwen PC, Hinrichs SH. Identification of Aspergillus Species Using Internal Transcribed Spacer Regions 1 and 2. J Clin Microbiol. 2000;38(4):1510-1515.

35. Altschul SF, Madden TL, Schaffer AA, et al. Gapped BLAST and PSIBLAST: a new generation of protein database search programs. Nucleic Acids Res. 1997;25(17):3389-3402.

36. Breitenbach J, Kraenzlin F. Fungi of Switzerland. Vol 2: Non-gilled fungi. Lucerne: Verlag Mykologia; 1986.

37. Mendonça RT, Jara JF, González V, et al. Evaluation of the white rot fungi Ganoderma australe and Ceriporiopsis subvermispora in biotechnological applications. $J$ Ind Microbiol Biotechnol. 2008;35(11):1323-1330.

38. Hawksworth DL. The magnitude of fungal diversity: the 1.5 million species estimate revisited. Mycological Research. 2001;105(12):1422-1432.

39. Rojas-Sandoval J, Acevedo-Rodríguez P. Naturalization and invasion of alien plants in Puerto Rico and the Virgin Islands. Biological Invasions. 2015;17(1):149-163.

40. Hogan JA, Zimmerman JK, Uriarte M, et al. Land use history augments environment-plant community relationship strength in a Puerto Rican wet forest. Journal of Ecology. 2016;104(5):1466-1477.

41. Rossman AY. A strategy for an all-taxa inventory of fungal biodiversity. In: Biodiversity and Terrestrial Ecosystems. Taiwan: Academia Sinica; 1995. 169-194 p.

42. Shi J, Sharma-Shivappa R, Chinn M, et al. Effect of microbial pretreatment on enzymatic hydrolysis and fermentation of cotton stalks for ethanol production. Biomass and Bioenergy. 2009;33(1):88-96.

43. Herbarium and Culture Collection. United States: Department of Agriculture Forest Products Laboratory, Center for Forest Mycology Research. 2012. 